\title{
Fabrication of Extrudate Filaments from Waste Polyethylene Terephthalate Plastics for 3D Printers
}

\author{
${ }^{*}$ Favour C. Eboh, Opeyemi Osideko, and Modupe Onitiri \\ Department of Mechanical Engineering, University of Lagos, Nigeria \\ \{favourking95 | osideko99\}@gmail.com | monitiri@unilag.edu.ng \\ Received: 10-MAY-2021; Reviewed: 17-JUN-2021; Accepted: 20-JUN-2021 \\ http://dx.doi.org/10.46792/fuoyejet.v6i2.636
}

\begin{abstract}
The use of 3D printers for manufacturing processes comes with the challenge of filament replacement for subsequent processes. This aforementioned including the environmental problems posed by plastics wastes formed the basis for the current work which is focused on design and construction of a simple single extruder for the production of filaments from waste polyethylene terephthalate (PET) plastics for rapid prototyping machines and 3D printers. Three Band heaters were used to melt the PET plastics and a screw was used to move the melted PET plastics longitudinally along the barrel. The screw is consisted of three zones namely feed zone, compression zone and metering zone. The temperature of the band heaters is controlled by a Digital temperature controller. This paper describes the design, fabrication and testing of a filament extruder. A $2 \mathrm{~mm}$ die was used to extrude the filament to1.75 $\mathrm{mm}$. The performance of the system was quantified through relevant tests and the findings reported. When the barrel and die assembly are at $200^{\circ} \mathrm{C}$, melting begins to occur and at $230^{\circ} \mathrm{C}$, the extrudate begins to appear at the metering zone. The energy efficiency of the system was found out to be $75.2 \%$.
\end{abstract}

Keywords-3D printer, Design, Extruder, Filament, Polyethylene terephthalate

\section{INTRODUCTION}

Tost of the 3D printers are based on the fused deposition, which uses mostly Acrylonitrile Butadiene Styrene (ABS) and Poly lactic Acid (PLA) as the printer material. A screw extruder is a mechanical device which consists of screw conveyor which has a variable pitch and increasing core diameter rotating inside a heated cylindrical chamber. The increase in pressure due to decrease in volume causes the input material to be conveyed along the length of the rotating screw. The input material is melted as it moves through the barrel and later forced out through the extrusion head. The extrusion head has a nozzle with the orifice shaped according to required extrudate geometry. A screw extruder can be used to ensure produce filaments for 3D printers. The extruder of the $3 \mathrm{D}$ printer uses a wired filament of diameter $1.75 \mathrm{~mm}$ or $3 \mathrm{~mm}$ for printing. Most of the manufacturing units, companies, colleges who have the 3D printer in-house are dependent on 3rd party supplier, and need to buy the 3D printer filament from these suppliers (Smith, 1978).

Considering the fact that there are several methods in which materials are extruded (Ugboya et al., 2019) modeled and fabricated a single screw extruder for melting and mixing of different categories of polymer. In other to eliminate some of the challenges encountered with existing extruders, a heating element was embedded in the screw including a thermostat to regulate and limit the amount of heat in the barrel. Considering the production rate, (Abebe et al., 2020) designed an automated integrated shredder and extrusion machine on a small-scale use with an efficiency of $80 \%$ and a capacity of $20.4 \mathrm{~kg}$ of plastic blocks finished per hour, a working capacity of up to three cycles per minutes and a rate of production of 180 products per hour. The machine parts were simulated using CATIA, ANSYS and FESTO.
Hosseini et al. (2012) investigated various process parameters by friction stir extrusion such as transverse speed rate and rotational speed of the die on the microstructure and physical properties of the extrudate by employing inherent heating due to friction and extensive deformation of plastic.

For the design and development of extruder for plastics of different types (Dubashi et al., 2005), in their work on extrusion as a process of making 3D printing filament, stated that liquid plastic is forced through an extrusion die and is formed into thin long strand of plastic. Also, (Proscher, 2012) in his work to extrude the plastic filament manufacturing for 3D-printer at large, which comprises of fabrication of a low case style extruder unit, stated that it comprises of the purchased CAD - software assisted together with the electronic fabrication of a first-generation extruder unit. Hence, the application of the universal parts to a reasonable extent in order to minimize the manufacturing cost is a unit target. The other target is the generation of unwavering extrusion process that has the capacity to recycle slashed plastic milk bottles.

This current work intends to design, construct and test a 3D printer filament making machine for small manufacturing units and colleges at low cost. The machine would be made from readily available materials sourced out from the local market, and the extruded filaments will be made from waste PET plastic. The filaments produced will be air-cooled and will the collected through a collection unit.

\footnotetext{
*Corresponding Author

Section C- MECHANICAL ENGINEERING \& RELATED PHYSICAL SCIENCES Can be cited as:

Eboh F., Osideko O. and Onitiri M. (2021): Fabrication of Extrudate Filaments from Waste Polyethylene Terephthalate Plastics for 3D Printers, FUOYE Journal of Engineering and Technology (FUOYEJET), 6(2), 78-82. http://dx.doi.org/10.46792/fuoyejet.v6i2.636
} 


\section{Methodology \\ 2.1 Design Analysis and Calculation}

The plastic filament extruder has a dimension of 1218.99 $\mathrm{mm} \times 311.39 \mathrm{~mm} \times 466.18 \mathrm{~mm}$ (see Fig. 2). Its major components are constructed from locally sourced materials. which are the major extruder components. It is powered by $500 \mathrm{~W}$ electric motor with a rotating speed of $1350 \mathrm{rpm}$.
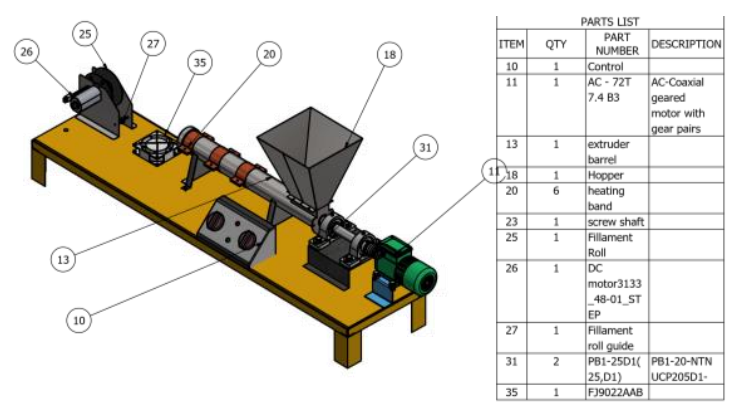

Fig. 1: Single screw extruder showing (1) band heaters, (2) extrusion barrel, (3) screw, (4) die, (5) hopper, (6) bearings, (7) filament extractor, (8) cooling fans, (9) filament roll, (10) filament roll guide, (11) AC geared motor, (12) DC geared motor, (13) control unit.

Plastic pellets are fed into the machine through the feed hopper and conveyed by the screw as it rotates along the barrel, to the die where it is discharged as filament. The hopper is a rectangular cross-sectioned reversed frustrum with a height of $160 \mathrm{~mm}$. The upper and the lower rectangular dimensions are $200 \mathrm{~mm}$ by $205 \mathrm{~mm}$ and 85 $\mathrm{mm}$ by $45 \mathrm{~mm}$ respectively. The horizontal extrusion barrel mounted on a triangular frame is a cylindrical structure made from a mild steel pipe of $36 \mathrm{~mm}$ internal diameter, thickness of $6 \mathrm{~mm}$ and length of $400 \mathrm{~mm}$. This extrusion barrel has a $34 \mathrm{~mm}$ outer diameter screw/auger inside it that rotates to convey the plastic pellets from the inlet point at the hopper towards the die. The screw pitch, constant flight angle and channel width are $30 \mathrm{~mm}, 26.7^{\circ}$ and $24 \mathrm{~mm}$ respectively. The barrel transfers heat to the conveyed pellets from a three $1500 \mathrm{~W}, 220 \mathrm{~V}$ heater band clamped on it. The barrel discharges the molten pellets through the die which is screwed in at the exit end of the system away from the hopper. The die is made of 360 brass with $2 \mathrm{~mm}$ hole (orifice) which is the diameter of the extruded plastic filament.

The plastic filament extruder was designed based on the consideration of design for the barrel, design for the gear, design for the shaft, and design for the nozzle.
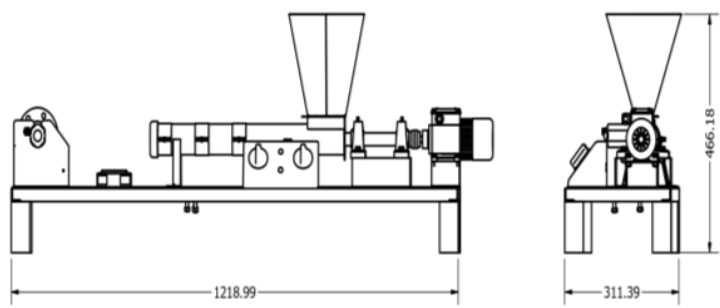

Fig. 2: Schematic of the filament extruder showing the various components

\subsection{DESIGN OF THE BARREL}

The barrel of the filament Extruder was design using the following parameters: Length of barrel, $\mathrm{L}=525 \mathrm{~mm}$, Internal diameter, $\mathrm{d}=35 \mathrm{~mm}$, External diameter, $\mathrm{D}=60$ $\mathrm{mm}$. The volume $\mathrm{V}_{\mathrm{b}}$ of the barrel was determined to be $0.002 \mathrm{~m}^{3}$ as proposed by (Khurmi and Gupta, 2005) in equation (1).

$$
V_{b}=A_{b} L_{b}
$$

where $A_{b}$ is the area of the barrel $=0.05002044 \mathrm{~m}^{2}$ and $\mathrm{L}_{b}$ is the barrel length $=0.4 \mathrm{~m}$.

\subsection{Determination Of CAPACity Of The Extrusion CONVEYOR}

The capacity of the horizontal acting auger conveyor was calculated using the equation given by (Khurmi and Gupta, 2005) as shown in equation (2).

where;

$$
Q=60 n \phi p \gamma\left(D^{2}-d^{2}\right) \frac{\pi}{4}
$$

$\mathrm{Q}=$ capacity of the screw conveyor in the barrel, $\mathrm{t} / \mathrm{h}$; bulk density of conveyed material, $300 \mathrm{~kg} / \mathrm{m}^{3} ; \mathrm{n}=$ number of screw rotation (assume $500 \mathrm{rpm}$ ); $\emptyset=$ factor induced for horizontal conveyor, 1 ; $\mathrm{p}=$ conveyor pitch, $0.05 \mathrm{~m}$; $\mathrm{D}=$ pitch diameter of conveyor, $0.112 \mathrm{~m}$, and $\mathrm{d}=$ shaft

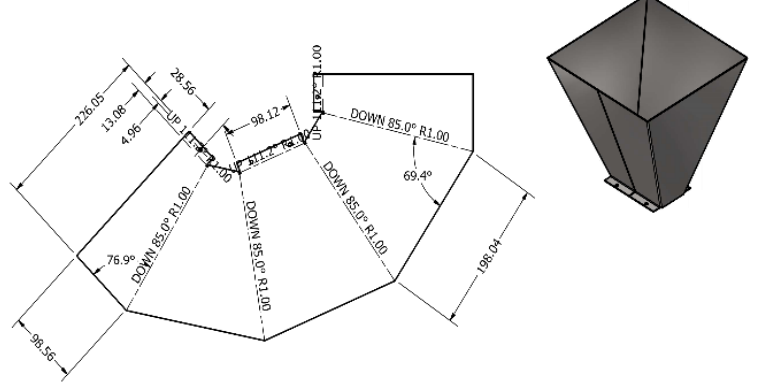

Fig. 3: Schematic diagrams of the Hopper

diameter, $0.03 \mathrm{~m}$.

\subsection{HOPPER Volume CALCULATIONS}

The hopper was made from mild steel sheet metal and was designed as wedged shaped hopper. There are no specifications for hopper design. A truncated rectangular pyramid hopper was adopted (see Fig. 3).

Volume of the pyramid $\mathrm{V}=\frac{1}{3}\left(A_{1}+A_{2}+\sqrt{A_{1} A_{2}}\right) h$

Where, $A_{1}=$ area of top base

$A_{2}=$ area of bottom base

$h=$ Height of bottom pyramid from $\left(A_{1}\right.$ to $\left.A_{2}\right)$

$$
\begin{gathered}
A_{1}=39,029.76 \mathrm{~mm}^{2} \\
A_{2}=2,802.3 \mathrm{~mm}^{2}
\end{gathered}
$$

$V=2788512.63 \mathrm{~mm}^{3} \cong 2.7885 \mathrm{~m}^{3}$ 


\subsection{DESIGN OF SCREW / AUgER}

A horizontal screw conveyor or auger (Fig. 4) was designed and partially tapered with a constant pitch of $30 \mathrm{~mm}$. The extruder screw is divided into three sections, namely; feed section, compression section and metering section. The feed section which has a uniform channel width collects the solids PET from the hopper into the extruder. The PET solids are further mixed together and compressed into the compression section of the screw. The metering section is where the PET is melted and stabilized to a uniform temperature and composition. According to (Campbell, 2003), the following were the assumptions for the screw calculations; (i) flow is developed fully, (ii) channels of flow are filled completely, (iii) absence of slip at boundary surfaces, (iv) no flow leakage over the flight tips, (v) all channel corners are square, (vi) flow is Newtonian and isothermal, and (vii) channel dimensions are constant.

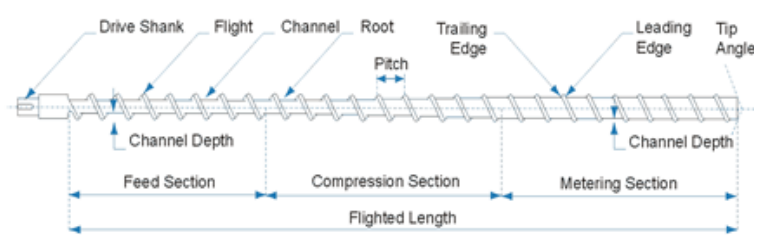

Fig. 4: Schematic of extruder screw

The geometry of the extruder screw (see Fig. 4) which includes the screw pitch, flight width, channel width, channel depth and pitch angle was designed using the equations provided by (Potente et al., 1994). Equations (3) to (9) were used to compute the relationship between the outer screw diameter and the distance between the axis of a flight screw; intermeshing angle $(\propto)$, flight angle $(\beta)$, screw pitch $(t)$, angle of pitch $\left(\varnothing_{s}\right)$, channels width $\left(b_{\max }\right)$ and depth $\left(h_{\max }\right)$.

$$
\begin{aligned}
& \frac{a}{D_{s}} \leq \frac{\sqrt{2}}{2} \\
& \propto=2 \cos ^{-1} \frac{a}{D_{s}} \\
& \beta=\frac{\pi}{i}-\propto \\
& t=\frac{2 \pi l_{k n}}{\delta j_{k n}} \\
& \emptyset_{s}=\tan ^{-1} \frac{t}{\pi D_{s}} \\
& b_{\max }=t \cos \emptyset_{s}-\epsilon_{\max } \\
& h_{\text {max }}=D_{s}-a
\end{aligned}
$$

where, $l_{k n}=28 \mathrm{~mm}$ right-handed standard screw, $\delta=1.57$ radians, $j_{k n}=$ standard screw element $=2$, and $a=$ distance between axis of flight $(\mathrm{mm})$.

The dimensions of the extruder screw with a total length of $895 \mathrm{~mm}$ are presented in Table 1 .

\subsection{FLOW ANALYSIS OF THE EXTRUDER}

The overall flow of pellets in the extruder is given as; Overall or total flow $=$ Rotational or drag flow pressure flow - leak flow

The leak flow is negligible because it is assumed that flow velocity is zero at the clearance between the barrel wall

\begin{tabular}{|c|c|c|c|c|}
\hline \multicolumn{3}{|c|}{ Diameter (D) } & \multicolumn{2}{|l|}{$50 \mathrm{~mm}$} \\
\hline \multicolumn{3}{|c|}{ Flighted Length } & \multicolumn{2}{|c|}{$500 \mathrm{~mm}(10 \mathrm{D})$} \\
\hline \multicolumn{3}{|c|}{ Feed Section Length } & \multicolumn{2}{|c|}{$225 \mathrm{~mm}(4.5 \mathrm{D})$} \\
\hline \multicolumn{3}{|c|}{ Compression Section } & \multicolumn{2}{|c|}{200 mm (4D) } \\
\hline \multicolumn{5}{|l|}{ Length } \\
\hline \multicolumn{3}{|c|}{ Metering Section Length } & \multicolumn{2}{|c|}{$75 \mathrm{~mm}(1.5 \mathrm{D})$} \\
\hline \multicolumn{3}{|c|}{ Compression Ratio } & \multicolumn{2}{|l|}{3} \\
\hline \multicolumn{3}{|c|}{$\begin{array}{l}\text { Constant Screw Pitch } \\
\text { (Flight lead) }\end{array}$} & \multicolumn{2}{|c|}{$50 \mathrm{~mm}(1 \mathrm{D})$} \\
\hline \multicolumn{3}{|c|}{$\begin{array}{l}\text { Channel Depth Feed } \\
\text { Section }\end{array}$} & \multicolumn{2}{|c|}{$7.5 \mathrm{~mm}(0.15 \mathrm{D})$} \\
\hline \multicolumn{3}{|c|}{$\begin{array}{l}\text { Channel Depth Metering } \\
\text { Section }\end{array}$} & \multicolumn{2}{|c|}{$3.5 \mathrm{~mm}(0.07 \mathrm{D})$} \\
\hline \multicolumn{3}{|c|}{ Channel Width } & \multicolumn{2}{|c|}{$2.5 \mathrm{~mm}(0.05 \mathrm{D})$} \\
\hline \multicolumn{3}{|c|}{ Flight Width } & \multicolumn{2}{|c|}{$5 \mathrm{~mm}(0.1 \mathrm{D})$} \\
\hline \multicolumn{3}{|c|}{ Flight Angle } & \multicolumn{2}{|l|}{$17.65^{\circ}$} \\
\hline \multicolumn{3}{|c|}{ Screw Tip Angle } & \multicolumn{2}{|l|}{$120^{\circ}$} \\
\hline $\begin{array}{l}\text { Flight to } \\
\text { Root } \\
\text { Radius }\end{array}$ & $\begin{array}{l}\text { Feed } \\
\text { Section }\end{array}$ & & $\begin{array}{l}\text { pression } \\
\text { on }\end{array}$ & $\begin{array}{l}\text { Metering } \\
\text { Section }\end{array}$ \\
\hline $\begin{array}{l}\text { Leading } \\
\text { Edge } \\
\text { Radius }\end{array}$ & $7.5 \mathrm{~mm}$ & 7.5 & $3.5 \mathrm{~mm}$ & $2.5 \mathrm{~mm}$ \\
\hline $\begin{array}{l}\text { Trailing } \\
\text { Edge } \\
\text { Radius }\end{array}$ & $5 \mathrm{~mm}$ & $5-2$ & & $2 \mathrm{~mm}$ \\
\hline
\end{tabular}
and outer diameter of the screw (Campbell, 2003). Therefore,

Total mass flow $=$ Mass drag (rotational flow) mass pressure flow
Table 1. Dimensions of extruder screw

According to Campbell (2003), the mass drag (rotational flow), $Q_{\text {md }}$ was determined as $15.6 \mathrm{~kg} / \mathrm{h}$ from equation (10).

$$
Q_{m d}=\frac{P \rho_{m} V_{b z} W H_{m}}{2}
$$

where; $\mathrm{Om}=$ melt density of resin at $250{ }^{\circ} \mathrm{C}\left(960 \mathrm{~kg} / \mathrm{m}^{3}\right) ; \mathrm{Vbz}$ $=\mathrm{z}$ component of the screw velocity at the barrel wall gotten from equation (11) as $0.058 \mathrm{~m} / \mathrm{s}$ according to (Campbell, 2003)

$$
V_{b z}=\pi N D_{b} \operatorname{Cos} \theta
$$

Where $\mathrm{N}$ is the screw rotational speed in rev/s $(1.08 \mathrm{rev} / \mathrm{s}$ that is $65 \mathrm{rpm}$ )

Also, the mass pressure flow, $\mathrm{Q}_{\mathrm{mp}}$ was determined as $1.71 \mathrm{~kg} / \mathrm{hr}$. from equation (14).

$$
Q_{m p}=\frac{P_{\rho m} W H^{3}}{12 \eta} \frac{\partial Z}{\partial z}
$$

where;

$\eta=$ Shear viscosity of molten resin polymer at average channel temperature $\left(2000 \mathrm{Ns} / \mathrm{m}^{2}\right)$

$\frac{\partial P}{\partial z}=$ Pressure gradient in the $\mathrm{z}$ direction channel $(1.8$ $\stackrel{\mathrm{MN}}{\mathrm{M}} / \mathrm{m}^{2}$ per $\mathrm{m}$ ) (Campbell, 2003)

The total mass flow rate of the extruder, $\mathrm{Q}_{\mathrm{mt}}$ was determined as $13.89 \mathrm{~kg} / \mathrm{hr}$. from equation (15).

$$
Q_{m t}=Q_{m d}-Q_{m p}
$$

$Q_{m t}$ is also the throughput capacity (TP), of the extruder. The throughput of the extruder was also alternatively determined as $13.89 \mathrm{~kg} / \mathrm{hr}$. from equation (16).

$$
T P=\frac{60 \pi}{4}\left(D_{S}^{2}-D_{C}^{2}\right) L_{S} N \varphi \rho_{m}
$$

Where $\varphi$ is the degree of pellet fill (0.875).

The Volumetric flow rate, $Q_{t}$ of the extruder was determined as $0.000446 \mathrm{~m}^{3} / \mathrm{s}$ using equation (17), (18) and (19) (Campbell, 2003)

$$
\begin{aligned}
& Q_{t}=Q_{d}-Q_{p} \\
& Q_{d}=\frac{P V_{b z} W H_{m}}{2}
\end{aligned}
$$




$$
Q_{p}=\frac{P W H^{3}}{12 \eta} \frac{\partial p}{\partial z}
$$

where $Q_{d}$ and $Q_{p}$ are volumetric drag flow and pressure flow, respectively in $\mathrm{m}^{3} / \mathrm{s}$.

The maximum pressure, $P_{\max }$ in the extruder was determined as $4.3 \mathrm{MN} / \mathrm{m}^{2}$ using equation (20) as proposed by (Campbell, 2003).

$$
P_{\max }=\frac{6 \pi D_{S} L_{m} N \eta}{H^{2} \tan \theta}
$$

\subsection{Determination of the Material Hold Up/ Volume CAPACITY OF THE EXTRUDER}

The equation for evaluating the hold up of materials in the barrel of a screw extruder was proposed by (Khurmi and Gupta, 2005) and it was used to evaluate the material hold up in the extruder barrel as $0.0000149 \mathrm{~m}^{3}$ as expressed in equation (21).

$$
V_{m}=\varphi V_{\text {total }}
$$

where, $V_{m}$ is the material hold up in $\mathrm{m}^{3}$

$\varphi$ is the degree of fill $(87.5 \%)$

$V_{\text {total }}$ is the reaction volume of the extruder which is the difference between the barrel volume and volume of the screw/auger.

\subsection{DESIGN OF DIE}

The die (see fig. 5.) was designed using the following criteria. The proposed die must provide a uniform rate of flow of the materials through its exit gap, constantly provide a uniform melt temperature over the whole of the exit gap, produce a melt that has the same shear history for all parts of the exit gap. The failure to meet up with these criteria can possibly result to poor thickness distributed in the extrudate, poor dimensional inaccuracy, inappropriate melt stiffness, die swell behavior and poor appearance.

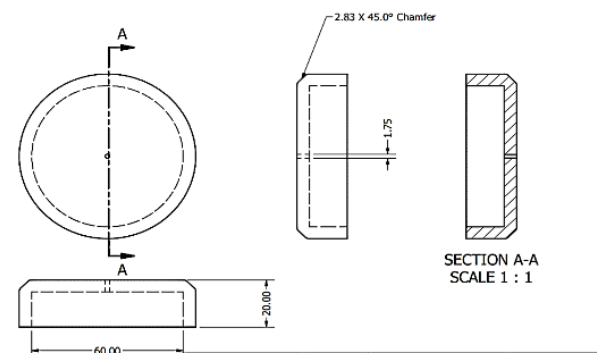

Fig. 5: Schematic diagram of the Filament Extruder die

Determination of die pressure: According to (Campbell, 2003), $P_{d}<0.5 P_{\max }$. Where $P_{d}$ is the die pressure i.e. $P_{d}$ is usually less than half of the maximum barrel pressure. Therefore, the die pressure, $\mathrm{P}_{\mathrm{d}}$ was determined to be 1.81 $\mathrm{MN} / \mathrm{m}^{2}$.

Determination of die heater power: The heating of the die was achieved using an electrical heating element (heater band) clamped on the outer part of the body with thermocouple deeply embedded and controlled by PID type temperature controller. The heating power of the die, $\mathrm{Ph}_{\mathrm{h}}$ was determined as $1500 \mathrm{~W}$ using equation (22) as proposed by (Dynisco, 2007).

$$
P_{h}=\frac{w C_{s p}\left(T_{2}-T_{1}\right)}{t}
$$

Where $\mathrm{w}=$ die weight $(0.42 \mathrm{~kg}) ; \mathrm{C}_{\mathrm{sp}}=$ specific heat capacity of die material $\left(375 \mathrm{~J} / \mathrm{kg}^{\circ} \mathrm{C}\right.$ for brass $) ; \mathrm{T}_{2}-\mathrm{T}_{1}=$ temperature rise $\left(250{ }^{\circ} \mathrm{C}-20^{\circ} \mathrm{C}\right)$; and $\mathrm{t}=$ time required to heat the die. However, three heaters, $1500 \mathrm{~W}$ each, were used so that heating time can be significantly reduced. One was attached to the die while the other was attached to the barrel.

\subsection{Selection of Prime Mover}

The power required by the screw, Ps conveyor was calculated from the expression given by (Khurmi and Gupta, 2005) as 0.00097 KW from equation (23).

$$
P_{s}=0.7355 C L_{S} Q_{m t}
$$

where $C$ is the constant coefficient of conveyed material usually taken to be 0.3 .

A $220 \mathrm{~V}, 500 \mathrm{~W}, 1: 10$ geared AC motor was used in this work.

\subsection{EXTRUdATE CoOling}

For the formed thermoplastic to retain its shape, heat must be removed from it. The amount of heat contained in the polymer melt is used to determine the quantity of heat to be removed and cooling needed. In this work, cooling was achieved by using a $12 \mathrm{~V}$ DC electric fan and the amount of heat removed from the extrudate was determined to be $1.75 \mathrm{~kW}$ as proposed by (John Goff and Tony Whelan, 2007) using equation (24).

$$
H_{c}=Q_{m t} C_{P}\left(T_{m}-T_{f}\right)
$$

where $H_{c}$ is the heat content of the polymer in watts $(\mathrm{W})$; $C_{P}$ is the polymer specific heat capacity $\left(1970 \mathrm{~J} / \mathrm{kg}^{\circ} \mathrm{C}\right) ; T_{m}$ is the melt temperature $\left(250{ }^{\circ} \mathrm{C}\right)$ and $T_{f}$ is the final temperature $\left(20^{\circ \circ} \mathrm{C}\right)$

\subsection{CONSTRUCTION}

The filament extruder (Fig. 6) assembly is made up of a cylindrical barrel housing a screw or auger and connected to a series of band heaters. The screw is supported at both ends by two ball bearings and connected to a geared electric motor. The shredded waste PET plastics (Fig. 7a) are gravity fed continuously into the system from the hopper. As the motor drives the auger, it then pushes the resin pellets towards the outlet point of the machine. The heat from the heating band is evenly distributed using asbestos ribbon which ensures the PET plastics soften and melt prior to being pushed continuously through a die. This action ensures the fabrication of continuous filament strand with the die geometry (Fig. 7b). Air cooling system was used to ensure solidification of the extrudate. The filament is pulled out of the die and rolled using a $12 \mathrm{~V}$ DC motor.

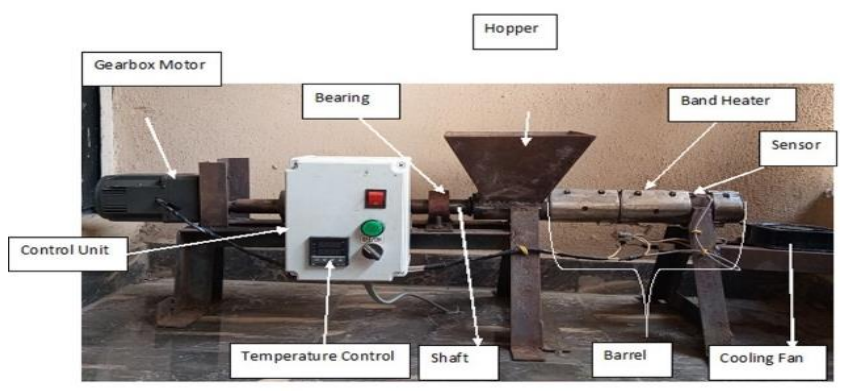

Fig. 6: Filament extruder 


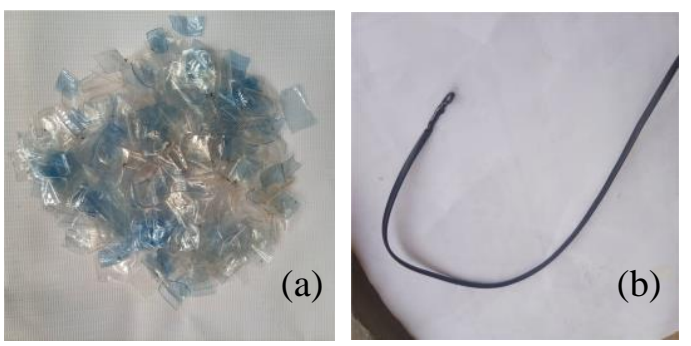

Fig. 7. (a) Shredded waste PET plastics and (b) filament fabricated using the single screw extruder

\section{RESULTS AND DISCUSSION}

The following tests conducted on the single screw extruder, namely; temperature evaluation at the three zones and cooling test of the extruded filament.

\subsection{Temperature Evaluation At The Three Zones}

Fig. 8 shows the results obtained from the temperature evaluation at the three zones. It was observed that after 30 minutes of heating, the temperature remained constant as the thermostat has a heating limit of $230{ }^{\circ} \mathrm{C}$.

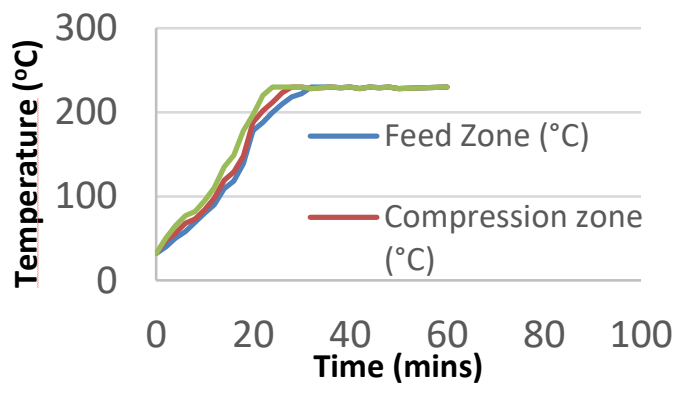

Fig. 8: Graphical results showing Temperature across the zones versus time curve

\subsection{COOLING TEST OF EXTRUDATE}

Fig. 9 shows the results obtained from the cooling test on the extrudate. During cooling from $230^{\circ} \mathrm{C}$ to $130^{\circ} \mathrm{C}$, the extrudates began to solidify after 20 minutes of fan cooling. Further cooling for additional 30 minutes reduces the temperature of the extrudate to a room temperature about $31^{\circ} \mathrm{C}$.

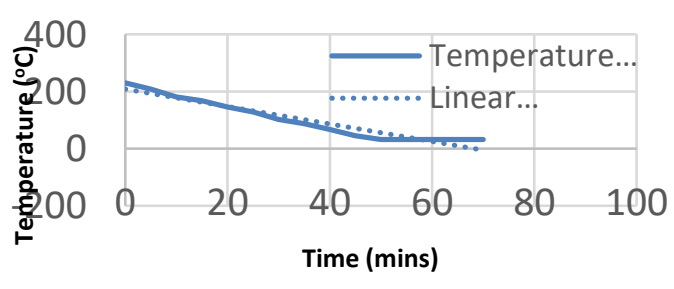

Fig. 9: Graphical results showing Cooling temperature against time

\subsection{EfFicienCy OF THE SYSTEM}

In the case of an extruder, the energy used for useful work $\left(\mathrm{E}_{\mathrm{u}}\right)$ is the energy used for material melting and forming through the die which is given by equation 25 :

$$
\mathrm{E}_{\mathrm{u}}=\mathrm{E}_{\text {in }}-\text { Elosses }
$$

where Ein is the total energy supplied to the extruder while Elosses is the total amount of energy wasted with no involvement in any useful work. Ein is the electrical energy supplied to the various devices such as drive motor, barrel and die heaters, motor cooling fan, barrel cooling fans, water pump and instruments in the control panel. Elosses include energy losses that occur in devices and other mechanical or functional systems such as transmission, forced and natural cooling. The motor and barrel/die heaters consume over $90 \%$ of the total energy supplied and account for the greatest energy losses. It is a major challenge in extrusion system to recover energy loss because it is largely dissipated into air or water. The energy efficiency of the extruder ( $\left.\eta_{\text {extruder }}\right)$ is given by:

$$
\begin{aligned}
& \eta_{\text {extruder }}=\frac{E_{\text {in }}-E_{\text {losses }}}{E_{\text {in }}} \times 100 \% \\
& \eta_{\text {extruder }}=\frac{\text { work output }}{\text { work input }} \times 100 \%
\end{aligned}
$$

where work output corresponds to the weight

Work output $\left(1000 \mathrm{~cm}^{3}\right)=253 \mathrm{~g}=0.253 \mathrm{~kg}$

Work input $=348 \mathrm{~g}=0.348 \mathrm{~kg}$

$$
\eta_{\text {extruder }}=\frac{0.253}{0.348} \times 100 \%=75.2 \%
$$

\section{CONCLUSION}

The single extruder for the fabrication of filaments from waste polyethylene terephthalate (PET) plastics for 3D printers and rapid prototyping machines was designed and constructed with an energy efficiency of $75.2 \%$. The results obtained from the temperature evaluation at the three zones shows that the temperature distribution across the zones is uniform; this could be ascribed to the high thermal conductivity of the metal used (Mild steel). With the barrel and die assembly at $200^{\circ} \mathrm{C}$, melting begins to occurs and at $230^{\circ} \mathrm{C}$, the extrudate begins to appear at the metering zone. The result for the thermal cooling shows that the cooling rate is directly proportional to the temperature of the surroundings.

\section{REFERENCES}

Alemayehu P.V.A.M., Reddy A.H., Mengistu N. and Woyessa L.N. (2020), Automatic waste plastic recycle machine integrated with extrusion hopper mechanism. International Journal of Innovative Technology and Exploring Engineering, 9(3), 1347-1356

Campbell J.L., (2003), Measurement of the L1 subshell fluorescent and Coster-Kronig yields of bismuth. Journals of Physics B: Atomic, Molecular and Optical Physics, vol. 36, no. 15.

Dubashi J., Grau B., Mckernan A., (2015), AkaBot 2.0: pet 3D printing filament from waste plastic, Mechanical Engineering Senior thesis, Sanata Clara University.

Hosseini A., Azarsa E. and Davoodi B., (2012) Effect of process parameters on the physical properties of wires produced by friction method. IJAET: International journal of advances in engineering and technology, ISSN 2231-1963.

John G., Tony W., (2007) The Dynisco extrusion processors handbook, 2nd ed.

Khurmi R.S., Gupta J.K., (2005), A textbook of machine design, 14th edition (S.I. Units) Ram Nagar New Delhi: Eurasia Publishing house pvt. 1td.

Potente H., Ansahl J. and Klarholz B., (1994), Design of tightly Intermeshing co-rotating twin screw extruders. International Polymer Processing, vol. 9, no.1, pp. 11-25

Proscher D., (2012), Extruder to recycle plastic milk bottles. Hochschule Ausburg University of Applied Science.

Smith H.V., (1978), Some criteria for the successful commercial recycling of heterogeneous plastics wastes, conservation and recycling. Pergamum Press Ltd, vol. 2, no. 2, pp.178-201.

Ugboya A.P., Orliamenbi A., Aigbojie O.E., (2019) The design and construction of a single screw extruder. Journal of Multidisciplinary Engineering Science and Technology (JMEST), vol.6, no.7. 